Jurnal Ekobis Dewantara Vol. 3 No. 2 Mei 2020

\title{
EFEKTIVITAS KOMPENSASI PELENGKAP UNTUK PENINGKATAN KINERJA KARYAWAN \\ (STUDI PADA PDAM TIRTA MUKTI KABUPATEN CIANJUR)
}

\author{
Kendra Nur Ghibrani ${ }^{1}$, Acep Samsudin ${ }^{2}$, Nor Norisanti ${ }^{3}$ \\ Fakultas Ilmu Admnisitrasi Dan Humaniora, Universitas Muhammadiyah Sukabumi \\ Email: $\underline{\text { m.ken31@ummi.ac.id }{ }^{1} \text { acepsamsudin@ummi.ac.id }{ }^{2} \text { nornorisanti@ummi.ac.id }{ }^{3}}$
}

\section{Intisari}

Pemberian kompensasi pelangkap sangat positif diterapkan dalam suatu perusahaan, dan dirancang tidak hanya untuk kepentingan karyawan namun juga untuk kepentingan perusahaan, antara lain bagi karyawan untuk mencegah agar tidak timbul mengenai permasalahan karyawan misalnya seperti turn over karyawan dan absensi. Perusahaan harus dapat melakukan kebijakan yang positif agar karyawan yang ada terdorong untuk mengembangkan dan meningkatkan kinerja karyawan dari segi kualitas dan kuantitasnya, sehingga mereka mampu memenuhi tuntutan pekerjaan yang pada akhirnya tercapailah tujuan perusahaan tersebut.

Penelitian ini menggunakan metode kuantitatif. Penelitian ini Populasinya adalah karyawan PDAM Tirta Mukti. Populasi berjumlah enam puluh responden pada PDAM Tirta Mukti. Naik turunnya kinerja karyawan pada PDAM Tirta Mukti dipengaruhi oleh kompensasi pelengkap sedangkan yang lainnya diperngaruhi oleh variabel lain. Berpengaruh positif dan signifikat antara hubungan kompensasi pelangkap terhadap kinerja karyawan. Hasil dari uji t kompensasi pelengkap berpengaruh secara parsial terhadap kinerja karyawan pada PDAM Tirta Mukti.

Kata Kunci: Kompensasi Pelengkap, Kinerja Karyawan

\begin{abstract}
The provision of trapping compensation is very positive applied in a company, and is designed not only for the benefit of employees but also for the benefit of the company, among others for employees to prevent problems arising from employees such as employee turnover and absenteeism. Companies must be able to carry out positive policies so that existing employees are encouraged to develop and improve employee performance in terms of quality and quantity, so that they are able to meet the demands of work that ultimately achieves the company's goals.

This research uses quantitative methods. The research population is the employees of PDAM Tirta Mukti. The population is sixty respondents in PDAM Tirta Mukti. The ups and downs in employee performance at PDAM Tirta Mukti are affected by complementary compensation while others are influenced by other variables. Have a positive and significant effect between the relationship of pencer compensation on employee performance. The results of the complementary compensation t test partially affect the performance of employees at PDAM Tirta Mukti.
\end{abstract}

Keywords: Complementary Compensation, Employee Performance

\section{PENDAHULUAN}

Setiap perusahaan pada saat ini berlomba-lomba mencari sumber daya manusia sebagai karyawan yang berkualitas, yang bisa memajukan nama baik perusahaan, karena tanpa sumber daya yang berkualitas, sebuah perusahaan akan menghambat pencapaian tujuan, maka dari itu kualitas dan kinerja karyawan harus selalu di perhatikan dan di tingkatkan. Masalah sumber daya manusia menjadi faktor utama bagi perusahaan/organisasi, meskipun adanya fasilitas yang mendukung dan memadai, jika sumber daya manusianya tidak mendukung dengan baik dan ahli, 
kegiatan perusahaan tidak akan terselesaikan dengan baik dan teknologi secanggih apapun akan tetao sia-sia jika sumber daya manusianya tidak mendukung dan kompeten. Pentingnya sumber daya manusia tercermin dari strategi manajemen sumber daya manusia yang mensejajarkan kebutuhannya dengan pentingnya strategi di bidang lainnya.

Perusahaan bisa dikatakan berhasil jika memiliki karyawan dengan kinerja yang berkualitas oleh karena itu hampir setiap perusahaan selalu berupaya menerapkan strategi untuk meningkatkan kinerja para karyawannya dan berharap tujuan perusahaan bisa tercapai. Jika strategi yang perusahaan terapkan berhasil dan dapat meningkatkan kinerja karyawan maka perushaan akan banyak mendapatakan keuntungan selain tujuan perusahaan dapat tercapai karyawan juga dapat mengerjakan tugas-tugasnya kebih cepat dikerjakan dengan baik, tingkat kesalahan berkurang, dan karyawan akan lebih disiplin.

Salah satu yang menjadi faktor dalam meningkatkan kinerja karyawan adalah kompensasi maka dari itu kompensasi merupakan pemberian balas jasa dari perusahaan yang diterima oleh karyawan karena karyawan telah bekerja untuk perusahaan dalam mencapai tujuan perusahaan akan tetapi pemberian kompensasi gaji dan upah saja tidak cukup untuk meningkatkan kinerja karyawan perlu adanya kompensasi tambahan untuk karyawan dalam membantu mengerjakan tugas-tugasnya seperti salah satunya kompensasi fringe benefits atau kompensasi pelengkap.

PDAM Tirta Mukti Cianjur salah satu perusahaan yang menerapkan strategi untuk meningkatkan kinerja karyawan, PDAM Tirta Mukti Cianjur menerapkan sistem strateginya dengan memberi kompensasi yang membuat karyawan merasa sejahtera dengan gaji dan upah karyawan yang cukup memadai pada saat mereka masih aktif berkerja. Gaji karyawan PDAM Tirta Mukti Cianjur sudah memadai untuk memberikan penghargaan dalam rangka meningkatkan kinerja karyawan dan juga mencegah terjadinya turn over karyawan.

Akan tetapi berdasarkan hasil wawancara saya dengan beberapa karyawan PDAM Tirta Mukti Cianjur kompensasi pelengkap masih kurang diperhatikan dan diduga menjadi penyebab permasalahan penurunan kinerja karyawan, oleh karena itu peneliti menemukan permasalah mengenai kinerja karyawan yang menurun. Hal tersebut dilihat dari Laporan Buku Kinerja BUMD Penyelanggara SPAM dimana pringkat PDAM Tirta Mukti Cianjur di tahun 2019 menempati pringkat ke 85 nasional sedangkan pada tahun 2018 menempati pringkat ke 76 nasional. Tidak hanya tingkat nasional PDAM Tirta Mukti Cianjur juga mengalami penurunan pringkat tingkat provinsi dimana pada tahun 2019 menempati pringkat ke 15 sedangkan tahun 2018 menempati pringkat ke 14. Penurunan pringkat tersebut diduga disebabkan oleh kurang diperhatikannya pemberian kompensasi pelengkap.

Berdasarkan pemaparan diatas maka peneliti akan mengambil judul yaitu, "Efektivitas Kompensasi Pelengkap Untuk Peningkatan Kinerja Karyawan Pada Pdam Tirta Mukti Kabupaten Cianjur." Penelitian ini bertujuan untuk mengetahui apakah kompensasi pelengkap berpengaruh untuk meningkatkan kinerja karyawan pada PDAM Tirta Mukti Kabupaten Cianjur.

\section{TINJAUAN PUSTAKA DAN PENGEMBANGAN HIPOTESIS \\ Manajemen Sumber Daya Manusia}

Manajemen sumber daya manusia adalah salah satu yang memiliki peran penting didalam sebeua organisasi atau perusahaan karena masuisa merupakan asset paling berharga yang dapat membantu organisasi atau perusahaan dalam mencapai tujuan. Sutrisno (2019:3) telah mengemukakan "Manajemen sumber daya manusia (MSDM) merupakan bidang strategis dari organisasi, manajemen sumber daya manusia harus dipandang sebagai perluasan dari pandangan 
tradisional untuk mengelola orang secara efektif dan untuk itu membutuhkan pengetahuan tentang prilaku manusia dan kemampuan mengelolanya”.

\section{Perilaku Organisasi}

Bisa disebut perilaku organisasi merupakan sebuah pembelajaran yang memahami tingkah laku seseorang dalam suatu organisasi bagaimana dia bisa bekerja secara individu maupun kelompok serta berdampak pada peningkata kinerja. Menurut Miftah (2014:2) "Organisasi merupakan suatu kerangka hubungan yang berstruktur didalamnya berisi wewenang, tanggung jawab dan pembagian kerja untuk menjalankan fungsi tertentu".

\section{Kompensasi Pelengkap}

Kompensasi pelengkap atau kompensasi fringe benefits bisa menjadi alternatif sistem kompensasi yang diberikan sebagai balas jasa atas pengabdian karyawan tersebut yang dapat diwujudkan dalam pemberian fasilitas-fasilitas kepada karyawan dan bisa juga disebut sebagai kompensasi tambahan. Pengertian kompensasi pelengkap atau fringe benefit adalah "salah satu komponen dari sistem kompensasi, yaitu berupa kompensasi tambahan yang diberikan berdasarkan kebijakan organisasi yang baru-baru ini diperhitungkan" (Bahri, 2019). Sedangkan menurut (Priansa \& Suwanto, 2014:237) "kompensai pelengkap ialah kompensasi di luar gaji dan upah atau kompensasi tidak langsung, yang diberikan dalam bentuk program-program pelayanan dan kesejahteraan karyawan, yang di maksudkan untuk menciptakan kenyamanan dalam bekerja bagi karyawan". Adapula pengertian kompensasi fringe benefits menurut (Hasibuan, 2017:118) "adalah kompensasi tambahan (finansial atau non finansial) yang diberikan berdasarkan kebijaksanaan perusahaan terhadap semua karyawan dalam usaha untuk meningkatkan kesejahteraan mereka seperti tunjangan hari raya, uang pensiun, pakaian dinas, kafetaria, mushola, olahraga dan darmawisata".

Dan yang menjadikan ukuran untuk kompensasi pelengkap menurut (Priansa \& Suwanto, 2014:238) menyatakan yang dapat dijadikan untuk menilai kompensasi pelengkap adalah Jaminan social, jasa-jasa kepegawaian, dan terakhir asuransi tenaga kerja.

\section{Kinerja Karyawan}

Organisasi atau perusahaan yang berhasil dan efektif merupakan organisasi atau perusahaan dengan individu yang di dalamnya memiliki kinerja yang baik. Menurut Fatimah (dalam Nainggolan, 2018) "kinerja merupakan hasil kerja secara kualitas maupun kuantitas yang dicapai oleh anggota organisasi atau perusahaan dalam rangka pelaksanaan tugas sesuai dengan tanggung jawab yang telah dibebankan padannya. Semakin baik kinerja individu dalam kelompok, maka dapat dikatakan pula kinerja kelompok tersebut baik pula". Ada pula pengertian Kinerja Karyawan menurut (Mangkuprawira \& Hubeis 2007:153) "Kinerja adalah hasil dari proses pekerjaan tertentu secara terencana pada waktu dan tempat dari karyawan serta organisasi bersangkutan".

Menurut Bernaddin dan Russel (dalam Sumardjo \& Priansa, 2018:200) menyatakan bahwa pengukuran kinerja karyawan dapat digunakan dengan dimensi: kualitas, kuantitas, ketepatan waktu, efektivitas biaya, kebutuhan pengawasan, dan pengaruh interpersional.

\section{Pengembangan Hipotesis}

Hasil dari penelitian (Do, 2018) membuktikan bahwa program kompensasi pelengkap bukam hanya untuk kinerja individu tapi juga berpengaruh pada kenerja tim di sebuah perusahaan. Sama juga menurut penelitian dari (Subriyanti at al.,2018) perusahaan perlu memberikan balas jasa berupa kompensasi langsung, atau tidak langsung seperti asuransi, uang makan, dan transportasi dari hasil jerih payah kinerja mereka sehingga terciptanya proses pemberian kompensasi secara adil dan karyawan bersemangat untuk meningkatakan kinerja mereka. Dan selanjutnya dibuktikan 
dari penelitian (Hakim \& Muhdi, 2019) bila balas jasa perusahaan kepada karyawan memuaskan maka karyawan dapat meningkatkan kinerjanya.

\section{Hipotesis}

Hipotesis bisa diartikan sebagai dugaan sementara, hasil dari pemaparan diatas penulis telah menetapkan hipotesis sebagai berikut "Adanya pengaruh positif dan signifikat antara Kompensasi pelengkap terhadap kinerja karyawan".

\section{METODE PENELITIAN}

Penelitian ini termasuk dalam penelitian kuantitatif metode deskriftif dan metode asosiatif. Populasi dipenelitian ini adalah karyawan PDAM Tirta Mukti sebanyak 60 karyawan. Sampel yang diambil sebanyak 60 responden teknik pengambilan sampel yang digunakan dalam penelitian ini yaitu sampel jenuh. Teknik pengumpulan data dilakukan dengan menggunakan data primer dan sekunder. Data primer seperti observasi non participant observation, wawancara tidak tersetuktur, kuesioner skala likert. Data sekunder yaitu studi kepustakaan, dan dokumentasi.

Dengan menggunakan uji validitas dan reabilitas untuk mengukur setiap instrument valid tidaknya dan dapat dinyatakan terpercaya atau realiabel. Serta menggunakan uji asumsi klasik salah satunya uji normalitas kolmolgrov smirnov untuk menganalisis ketepatan model regresi bisa dinyatakan normal atau tidak normal. Sedangkan teknik analisis data yang digunakan dalam penelitian ini terdiri dari koefesien korelasi, koefesien determinasi, regresi linear sederhana, dan uji hipotesis secara parsial atau uji t.

\section{HASIL DAN PEMBAHASAN Hasil Uji Validitas Dan Reabilitas}

Tabel 1 Hasil Uji Validitas Dan Rebilitas

\begin{tabular}{|c|c|c|c|}
\hline NO & Variabel & Cronbach Alpha & Nilai r Hitung \\
\hline \multirow[t]{8}{*}{1} & \multirow[t]{8}{*}{ Kompensasi Pelengkap } & \multirow[t]{8}{*}{0,874} & 0,684 \\
\hline & & & 0,735 \\
\hline & & & 0,746 \\
\hline & & & 0,782 \\
\hline & & & 0,624 \\
\hline & & & 0,695 \\
\hline & & & 0,781 \\
\hline & & & 0,808 \\
\hline \multirow[t]{7}{*}{2} & \multirow[t]{7}{*}{ Kinerja Karyawan } & \multirow[t]{7}{*}{0,844} & 0,665 \\
\hline & & & 0,695 \\
\hline & & & 0,717 \\
\hline & & & 0,790 \\
\hline & & & 0,762 \\
\hline & & & 0,642 \\
\hline & & & 0,805 \\
\hline
\end{tabular}

Sumber: Olah Data SPSS 2020

Berdasarkan hasil uji validitas setiap insturtmen penelitian memiliki nilai $r$ hitung lebih besar dari $\mathrm{r}$ tabel yaitu 0,3 dengan ini seluruh item dinyatatakan valid dan bisa melanjutkan penelitian selanjutnya. Sedangkan hasil uji reabilitas setiap variabel memiliki nilai Cronbach Alpha yang lebih dari 0,60. Oleh karena itu dapat dijelaskan bahwa pengukuran dari variabel kuesioner 
adalah realiabel yang berarti hubungan antara kompensasi pelengkap (X) terhadap kinerja karyawan (Y) adalah kuat dan dapat dijadikan sebagai alat ukur pada analisis selanjutnya.

Tabel 2 Hasil Uji Normalitas

\begin{tabular}{llr}
\hline \multicolumn{3}{c}{ One-Sample Kolmogorov-Smirnov Test } \\
\hline & & \multicolumn{2}{c}{ Unstandardized } \\
& & Residual \\
\hline $\mathrm{N}$ & & 60 \\
\hline Normal Parameters ${ }^{\mathrm{a}, \mathrm{b}}$ & Mean & .0000000 \\
\cline { 2 - 3 } & Std. & 2.55026862 \\
\hline Most Extreme & Deviation & .055 \\
Differences & Absolute & .055 \\
\cline { 2 - 3 } & Positive & .044 \\
\cline { 2 - 3 } & Negative & .055 \\
\hline Test Statistic & & $.200^{\mathrm{c}, \mathrm{d}}$ \\
\hline Asymp. Sig. (2-tailed) & & \\
\hline Sumber: Olah Data SPSS 2020 & & \\
\end{tabular}

Hasil dari tabel uji normalitas kolmogrov-smirnov diatas menunjukan hasil siginifikansi total nilai kolmogrov-smirnov jumlahnya 0,200 dengan jumlah ini bisa dijelakskan bahwa total nilai signifikansi KS 0,200 lebih besar dari 0,05 (0.200 > 0,05) dengan hasil ini seluruh total jumlah populasi berdistribusi normal.

Tabel 3 Hasil Analisis Koefesien Korelasi

\begin{tabular}{lcrrr}
\hline \multicolumn{5}{c}{ Model Summary $^{\mathbf{b}}$} \\
\hline Model & R & R Square & Adjusted R Square & Std. Error of the Estimate \\
\hline 1 & $.655^{\text {a }}$ & .429 & .419 & 2.572
\end{tabular}

Sumber: Olah Data SPSS 2020

Tabel 4 Nilai R (Koefisien Korelasi)

\begin{tabular}{cll}
\hline Nomor & Interval Koefisien & Tingkat Hubungan \\
\hline 1 & $0,00-0,199$ & Sangat Lemah \\
\hline 2 & $0,200-0,399$ & Lemah \\
\hline 3 & $0,400-0,599$ & Cukup Kuat \\
\hline 4 & $0,600-0,799$ & Kuat \\
\hline 5 & $0,800-1,00$ & Sangat Kuat \\
\hline
\end{tabular}

Sumber: (Sugiyono, 2017)

Berdasarkan nilai dari signifikansi yaitu 0,00 lebih kecil dari nilai signifikansi $0,05(0,00<$ 0,05) maka bisa di nyatakan hubungan antara kompensasi pelengkap dengan kinerja karyawan yaitu berkorelasi. Sedangkan nilai pearson correlation 0,655 berdasarkan tingkat hubungan antara kompensasi pelengkap (X) dengan kinerja karyawan (Y) seperti pada tabel nilai $\mathrm{R}$ diatas berkorelasi kuat.

\section{Hasil Koefisen Determinasi}

Hasil dari tabel 3 diatas bisa di jelaskan bahwa nilai koefesien determinasi $\left(\mathrm{R}^{2}\right)$ sebesar $42 \%$ yang artinya bahwa naik turunnya kinerja karyawan pada PDAM Tirta Mukti bisa dijelaskan 
oleh pengaruh kompensasi pelengkap sebesar $42 \%$ sedangkan sisanya 58\% dari variabel-variabel lain yang berpengaruh dan bukan didalam penelitian ini.

Tabel 5 Hasil Uji Regresi Linear Sederhana

\begin{tabular}{|c|c|c|c|c|c|c|}
\hline \multicolumn{7}{|c|}{ Coefficients } \\
\hline \multirow[t]{2}{*}{ Model } & & \multicolumn{2}{|c|}{ Unstandardized Coefficients } & Standardized & $\mathrm{t}$ & Sig. \\
\hline & & $\mathrm{B}$ & Std. Error & Beta & & \\
\hline \multirow[t]{2}{*}{1} & (Constant) & 10.820 & 1.981 & & 5.461 & .000 \\
\hline & $\begin{array}{l}\text { Kompensasi } \\
\text { pelengkap }\end{array}$ & .484 & .073 & .655 & 6.603 & .000 \\
\hline
\end{tabular}

Sumber: Olah Data SPSS 2020

Tabel diatas menunjukan hasil dari nilai regresi linier sederhana, dan mendapatakan total nilai $b=0,484$ adapula total nilai $a=10,820$. Selanjutnya hasil nilai tersebut didapat persamaan regresi linear sederhana sebagai berikut:

$$
\begin{aligned}
& Y=a+b X_{1} \\
& Y=10,820+0,484 X_{1} \text { Arti persamaan tersebut adalah : }
\end{aligned}
$$

Total nilai konstanta memilki nilai a $=10,840$ menjelaskan jika variabel $\mathrm{X}$ kompensasi pelengkap tidak berubahan atau nilainya tetap nol maka nilai variabel Y kinerja karyawan dengan jumlah 10,840. Koefisien regresi kompensasi pelengkap berjumlah $b=0,484$ menjelaskan dari setiap peningkatan kompensasi pelengkap berjumlah satu satuan maka dari itu hal tersebut akan dapat meningkatkan kinerja karyawan sebesar 0,484.

\section{Uji Hipotesis Secara Parsial t}

Hasil dari tabel 5 variabel $X$ (kompensasi pelengkap) diperoleh nilai $t_{\text {hitung }}=6.603$ dengan taraf signifikansi 0,000. Dengan menggunakan batas 0,05 didapat $\mathrm{t}_{\text {tabel }}(\mathrm{df}=\mathrm{n}-\mathrm{k}-1=60-1-1=58)$ ini berarti $t_{\text {hitung }}>\mathrm{t}_{\text {tabel }}=6.603>1,671$ yang berarti Ha diterima dan Ho ditolak. Dengan ini berarti bahwa hubungan kompensasi pelengkap berpengaruh positif dan signifikat terhadap peningkatan kinerja karyawan.

\section{Pembahasan}

Kompensasi pelengkap terhadap peningkatan kinerja karyawan pada PDAM Tirta Mukti Kabupaten Cianjur memiliki pengaruh positif dan signifikan, hal tersebut dapat dilihat dan dijelaskan setelah pengujian hipotesis secara parsial atau uji t. Ada macam-macam jenis program kompensasi pelengkap seperti tunjangan, fasilitas, jaminan sosial, jasa-jasa kepegawaian, asuransi tenaga kerja, pembayaran upah pada saat tidak bekerja, dan masih banyak program kompensasi fringe benefits yang dapat mempengaruhi karyawa dalam meningkatkan kinerja karyawan. Dan berkaca pada penelitian sebelumnya yang dilakukan oleh (Hakim \& Muhdi, 2019) dimana hasil dari penelitian ini kompensasi seperti gaji pokok dan insentif saja tidak cukup untuk meningkatkan kinerja perlu diperhatikan dan diperbaiki pemberian kompensasi pelengkap, oleh itu kompensasi pelengkap bisa menjadi opsi tambahan sebagai balas jasa untuk mereka karena sudah bekerja dan untuk meningkatkan kinerja. Kompensasi pelengkap merupakan salah satu cara yang dapat diberikan oleh perusahaan sehingga dapat meningkatkan kinerja dan dapat berimbas pada tujuan organisasi atau tujuan perusahaan. 
Dan hal-hal lain yang dapat mempengaruhi untuk meningkatkan kinerja karyawan pada PDAM Tirta Mukti Kabupaten Cianjur yang dipengaruhi oleh faktor lain yang tidak diteliti dalam penelitian ini memiliki pengaruh.

\section{KESIMPULAN DAN SARAN Kesimpulan}

Hasil dari wawancara dan pembahasan diatas dengan ini bisa dijelaskanan bila perusahaan memberikan kompensasi pelengkap yang memadai maka kompensasi pelengkap dapat mempengaruhi peningkatan kinerja karyawan pada PDAM Tirta Mukti Kabupaten Cianjur. Hasil dari nilai koefesien determinasi $\left(\mathrm{R}^{2}\right)$ dijelaskan bahwa naik turunnya kinerja karyawan pada PDAM Tirta Mukti Kabupaten Cianjur dapat dilihat oleh kontribusi kompensasi pelengkap sedangkan sisanya dari variabel-variabel lain yang berpengaruh dan bukan didalam penelitian ini. Uji hipotesis menjelaskan adanya pengaruh positif dan signifikat antara hubungan kompensasi pelengkap terhadap kinerja karyawan. Hasil dari uji t kompensasi pelengkap berpengaruh secara parsial terhadap kinerja karywan pada PDAM Tirta Mukti Kabupaten Cianjur.

\section{Saran}

Berdasarkan kesimpulan diatas PDAM Tirta Mukti Kabupaten Cianjur juga perlu memperhatikan pemberian kompensasi pelengkap sebagai balas jasa diluar gaji dan upah karena karyawan juga memerlukan sarana pendukung seperti fasilitas, tunjangan, dan asuransi untuk meningkatkan kinerja karyawan agar dapat membantu perusahaan dalam mencapai tujuan.

\section{DAFTAR PUSTAKA}

Bahri, A. S. (2019). Sistem Kompensasi Pelengkap Program Layanan Karyawan Pada Organisasi Dakwah. Al-Hadid, Stid, 09(01), 85-100.

Do, T. T. (2018). How Spirituality, Climate, And Compensation Affect Job Performance. Social Responsibility Journal, 14(2), 396-409.

Hakim, A. R., \& Muhdi. (2019). Pengaruh Motivasi Kerja Dan Kompensasi Terhadap Kinerja Guru Smk Swasta Di Wilayah Timur Kabupaten Pemalang. Jurnal Pendidikan Ilmu Sosial, 29(2), $105-115$.

Hasibuan, M. (2017). Manajemen Sumber Daya Manusia Edisi Revisi (Cet. 21). Jakarta: Pt Bumi Aksara.

Mangkuprawira, S., \& Hubeis, A. (2007). Manajemen Mutu Sumber Daya Manusia (Pertama; Akhira, Ed.). Bogor: Ghalia Indonesi.

Miftah, T. (2014). Perilaku Organisasi Konsep Dasar Dan Aplikasinya (Cet. Ke-23). Jakarta: Raja Grafindo Persada.

Nainggolan, N. (2018). Pengaruh Beban Kerja, Kompensasi Dan Lingkungan Kerja Terhadap Kinerja Karyawan Pt Ex Batam Indonesia. Management, 1(4), 135-154.

Priansa, D., \& Suwanto, H. (2014). Manajemen SDM (Keempat). Bandung: Alfabeta, Cv.

Subriyanti, H., Yulianto, A., \& Setiawan, A. (2018). Pengaruh Kompensasi Terhadap Kinerja Karyawan Bagian Produksi Pada Pt. Kapuk Molek Jakarta. Ekonomi, 20(2).

Sugiyono. (2017). Metode Penelitian Kuantitatif, Kualitatif, Dan R\&D (25th Ed.). Bandung: Alfabeta, Cv.

Sumardjo, M., \& Priansa, D. (2018). Manajemen Pengembangan Sumber Daya Manusia KonsepKonsep Kunci (Kesatu). Bandung: Alfabeta, Cv.

Sutrisno, E. (2019). Manajemen Sumber Daya Manusia (Pertama). Jakarta: Prenadamedia Group. 